\title{
Direct Generation of Optical Diffractive Elements in Perfluorocyclobutane (PFCB) Polymers by Soft Lithography
}

\author{
Gregory P. Nordin \\ nordin@byu.edu \\ J. Ballato \\ P. C. Deguzman \\ S. Foulger \\ H. Shah
}

See next page for additional authors

Follow this and additional works at: https://scholarsarchive.byu.edu/facpub

Part of the Electrical and Computer Engineering Commons

\section{Original Publication Citation}

H. Shah, D. Smith, Jr., J. Ballato, S. Foulger, P. Deguzman, and G. Nordin, "Direct Generation of Optical Diffractive Elements in Perfluorocyclobutane (PFCB) Polymers by Soft Lithography," IEEE Photonics Tech. Let. 12(12), 165 (2)

\section{BYU ScholarsArchive Citation}

Nordin, Gregory P.; Ballato, J.; Deguzman, P. C.; Foulger, S.; Shah, H.; and Smith, D., "Direct Generation of Optical Diffractive Elements in Perfluorocyclobutane (PFCB) Polymers by Soft Lithography" (2000). Faculty Publications. 1105.

https://scholarsarchive.byu.edu/facpub/1105

This Peer-Reviewed Article is brought to you for free and open access by BYU ScholarsArchive. It has been accepted for inclusion in Faculty Publications by an authorized administrator of BYU ScholarsArchive. For more information, please contact ellen_amatangelo@byu.edu. 


\section{Authors}

Gregory P. Nordin, J. Ballato, P. C. Deguzman, S. Foulger, H. Shah, and D. Smith 


\title{
Direct Generation of Optical Diffractive Elements in Perfluorocyclobutane (PFCB) Polymers by Soft Lithography
}

\author{
H. Shah, D. Smith, Jr., J. Ballato, S. Foulger, P. Deguzman, and G. Nordin
}

\begin{abstract}
Optically diffractive line gratings with $0.58-\mu \mathrm{m}$ feature sizes have been generated in $100-\mu \mathrm{m}$ perfluorocyclobutane (PFCB) polymer films by direct micromolding using only a silicon master. Strong reflectivities from the green to red portions of the visible spectrum, depending on incident beam angle, were observed with $3 \mathrm{~dB}$ bandwidths of approximately $30 \mathrm{~nm}$. This "negative mold-free" technique permits, for the first time to our knowledge, feature reproduction at submicrometer size scales, eliminates several steps from conventional soft lithographic methods, and marks itself as a practical means for rapidly generating planar photonic structures that operate spectrally in the visible and the near IR telecommunication bands.
\end{abstract}

Index Terms-Gratings, optical polymers, PFCB, soft lithography.

\section{INTRODUCTION}

$\mathbf{P}$ OLYMERS are receiving global attention for a myriad of planar photonic and optoelectronic applications including optical interconnects [1], switches [2], splitters [3], and surface relief structures [4], to name just a few. This is a direct result of the relative ease and cost effectiveness with which planar polymeric structures can be fabricated, with respect to semiconductor and oxide analogs, while maintaining the requisite performance levels. From a materials point of view, polyaryl ethers containing perfluorocyclobutyl (PFCB) linkages are emerging as particularly attractive candidates for such photonic devices due to their wide range of complementary properties. These include, in comparison with more standard polymeric systems [i.e., poly(methyl methacrylate), PMMA] [5], excellent thermal and thermo-oxidative stability, high glass transition temperatures $\left(T_{g}\right)$, low moisture absorption, low

Manuscript received June 27, 2000; revised September 12, 2000. This work was supported by Clemson University, 3M Corporation, ARO under DURIP Grant DAAD19-99-1-0059, NASA-EPSCoR (SC Space Grant Consortium), Dow Chemical, and the National Science Foundation under CAREER Award ECS-9625040 and Grant EPS-9720653.

H. Shah and D. Smith, Jr. are with the Center for Optical Materials Science and Engineering Technologies, Department of Chemistry, Clemson University, Clemson, SC 29634 USA (e-mail: dwsmith@ clemson.edu).

J. Ballato is with the Center for Optical Materials Science and Engineering Technologies, Department of Ceramic and Materials Engineering, Clemson University, Clemson, SC USA 29634.

S. Foulger is with the Center for Optical Materials Science and Engineering Technologies, School of Textiles, Fiber and Polymer Science, Clemson University, Clemson, SC USA 29634

P. Deguzman and G. Nordin are with the Center for Applied Optics, Department of Electrical and Computer Engineering, University of Alabama, Huntsville, AL USA 35899.

Publisher Item Identifier S 1041-1135(00)10477-X. dielectric constant, highly variable refractive index through copolymerization, and the much-desired ability to process in the melt and solution form [6]-[8]. Furthermore, PFCB polymers are among the few known organics that possess low optical attenuations (measured at $<0.25 \mathrm{~dB} / \mathrm{cm}$ ) in the 1300 and 1550-nm telecommunication windows [8], [9].

Although other groups have reported the use of the thermosetting PFCB polymer (derived from tris(trifluorovinyloxyphenyl)ethane monomer) for optical applications [1]-[3], including examples with NLO chromophores [10], we have focused on property tunable PFCB optical copolymers prepared from the trifunctional monomer mentioned above and a wide assortment of novel bifunctional monomers [8]. We have found that random step-growth copolymers with a variable $T_{g}$ ranging from $120{ }^{\circ} \mathrm{C}$ to $350{ }^{\circ} \mathrm{C}$ and refractive indices ranging from $\sim 1.4$ to $\sim 1.6$ can be prepared easily by simple choice of comonomer [8]. In this work, we make use of a thermoplastic PFCB polymer prepared from bis(trifluorovinyloxy)biphenyl monomer to demonstrate the utility and versatility of this class of materials and describe a simple procedure, with experimental verification, for fabricating gratings that possess diffractive effects in the visible. This new approach does not involve photolithography but, rather, relies on photolithographically generated silicon masters from which PFCB-based microstructures are readily replicated. In addition, we have developed methods that preclude the need for elastomeric negative molds, enabling more cost-effective and reproducible prototypes.

\section{EXPERIMENTAL}

A complete description of the synthesis and comonomer properties is given in our previous works [7], [8]. PFCB polymers are prepared from trifluorovinyl aromatic ether (TVE) monomers via a free radical mediated thermal cyclopolymerization mechanism. They can be prepared neat or in solution at temperatures in excess of $150{ }^{\circ} \mathrm{C}$ and do not require initiators or catalysts. The polymers can be advanced to a precisely controlled viscosity, molecular weight, and polydispersity by simple heating. In this work, we utilize the $4,4^{\prime}$-bis(trifluorovinyloxy)biphenol (BPVE) [8] monomer since it exhibits the highest solution and melt viscosity of those amenable to photonic applications and therefore exemplifies the excellent processability of this class of fluoropolymers in general. Copolymerization with this monomer would only increase the solution and melt processability so that even smaller features than those generated here presumably could be prepared. 
Refractive indices of films cast prior to micromolding were measured using a wavelength tunable Abbe refractometer. Silicon master templates with $0.58-\mu \mathrm{m}$ step widths were generated by first coating $75-\mathrm{mm}$ diameter p-type $\langle 100\rangle \mathrm{Si}$ wafers with $1.1-\mu \mathrm{m}$-thick Shipley S1811 photoresist. This was followed by a 2-s exposure to ultraviolet light (intensity: 9.2 $\mathrm{mW} / \mathrm{cm}^{2}$ at $400 \mathrm{~nm}$ and $15.3 \mathrm{~mW} / \mathrm{cm}^{2}$ at $365 \mathrm{~nm}$ ) in a contact aligner using $1-\mu \mathrm{m}$ pitch chrome mask. After developing the photoresist, the line-grating pattern was transferred onto the silicon substrate by reactive ion etching with $\mathrm{CHF}_{3} / \mathrm{SF}_{6}$ gaseous mix. The BPVE films were cast onto the silicon master from a $15 \%(\mathrm{w} / \mathrm{w})$ mesitylene solution and subsequently dried via evaporation under a dry nitrogen flow at room temperature. Micrographs were obtained using a Hitachi S-4700 field emission scanning electron microscope. Reflectance spectra of the resulting molded PFCB structures were measured using a Gretag Macbeth CE741 goniospectrometer.

\section{RESULTS AND DISCUSSION}

Having previously demonstrated the potential of PFCB systems for optical applications from a materials standpoint [8], we focus our efforts here on developing nonphotolithographic processing methods toward device fabrication. Microfabrication using nonphotolithographic techniques (i.e., soft lithography) has been pioneered by Whitesides et al. [11] and recently used in our labs for patterning polynaphthalene network polymer structures [12]. These existing techniques involve the preparation of poly(dimethyl siloxane) (PDMS) molds/stamps by casting PDMS on a photolithographically generated silicon master containing the desired micropattern. The subsequent PDMS mold can be used in a variety of ways to replicate the features into the polymer on a given substrate. Two such examples are "micro-contact printing" $(\mu \mathrm{CP})$ and "micro- molding in capillaries (MIMIC) [12]," both of which also work well with PFCB polymers.

However, during our investigations, we found that the PDMS negative mold can be eliminated entirely when using PFCB polymers. Instead, PFCB replicas can be generated directly by molding the polymer against a silicon master, as is shown schematically in Fig. 1. Since PFCB polymers exhibit a low interfacial surface energy $\left[\gamma=18.5 \mathrm{~mJ} / \mathrm{m}^{2}\right.$ for polytetrafluoroethylene (PTFE) versus $\gamma=41.4 \mathrm{~mJ} / \mathrm{m}^{2}$ for polymethyl methacrylate (PMMA)] [13], the replicated structures can be lifted off easily from the master or the reverse when cast and patterned, without irreversible adhesion or defects. In addition, homopolymers or copolymers can be melt or solution cast onto the silicon masters containing the desired features; however, the lift-off process is simplified to a large extent by solution casting due to the plasticizing effect of the solvent, which subsequently is removed by vacuum drying.

PFCB gratings with $\sim 0.5-\mu$ m periodicities and $1-\mu \mathrm{m}$ step depths were prepared directly into a $100-\mu \mathrm{m}$ film and is shown in Fig. 2. It is noted for greater completeness that the BPVE polymer used here possesses a refractive index of 1.517 at 900 $\mathrm{nm}$, a $T_{g}$ of $165^{\circ} \mathrm{C}$, and a coefficient of thermal expansion of about $90 \mathrm{ppm}{ }^{\circ} \mathrm{C}$. The surface topography and spacing were found to be uniform over large areas $\left(>1 \mathrm{~cm}^{2}\right)$ without any no-

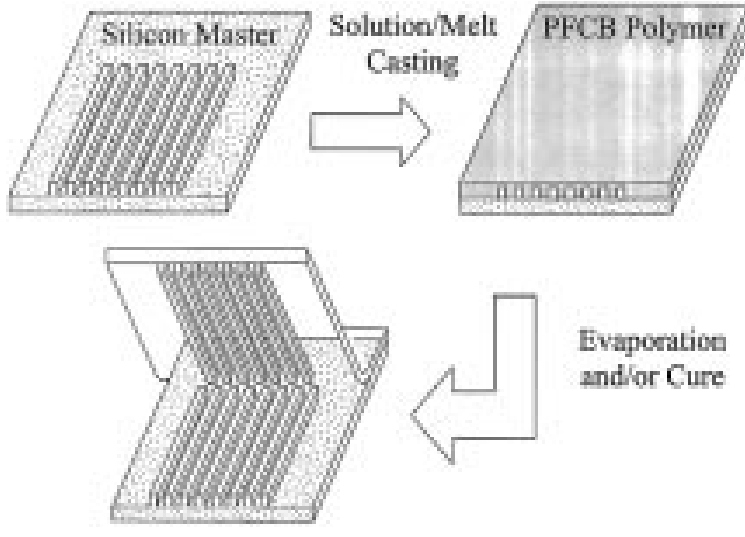

Fig. 1. Schematic illustrating direct micromolding using only a silicon master. The PFCB monomer is cast in either solution or melt form onto the Si master. Polymer containing replicated features is then removed after evaporation and/or further thermal polymerization.
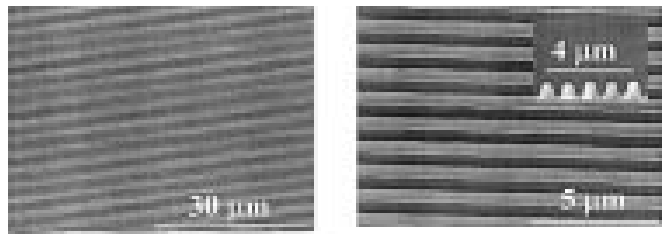

Fig. 2. Field emission scanning electron micrographs of line gratings replicated into the PFCB polymer by the Si master. Note uniformity and submicrometer feature sizes in the inset to the right-hand micrograph.

ticeable defects or distortions. There was observed a small degree of film coiling on removal from the Si master. However, the flexibility of the polymer makes it easily affixed to subsequent substrates. Further, annealing just below $T_{g}$ also can be used to eliminate a processing-induced curvature. The inset to Fig. 2 shows a rounding of the grating step; however, this is due to the act of cleaving that views the cross section and not the replication process itself. Fig. 3 shows the reflectivity spectra of the directly micromolded PFCB gratings, which are measured as a function of wavelength for a number of angles. As is clearly evident, the reflection from the Fig. 2 structure is strong with respect to baseline values (and readily is observable in ambient room light) with $3-\mathrm{dB}$ bandwidths for the diffraction peaks between 30 and $70 \mathrm{~nm}$, depending on the angle of view (i.e., reflected wavelength).

Although microfabrication procedures for the PFCB thermoset have been reported recently for planar waveguides with dimensions ranging from 5 to $50 \mu \mathrm{m}$ [1], the "negative mold-free" technique highlighted here demonstrates feature reproduction at submicrometer scales for the first time to our knowledge. The micrographs of Fig. 2 and the diffraction quantified in Fig. 3 underlie another important finding of this work that stems from both the technique and the choice of PCFB polymer family. Such an approach for fabricating submicrometer features that produce visible effects are also well suited for generating the necessarily larger structures associated with diffractive elements (Bragg gratings/filters or planar photonic crystal structures for example), planar waveguides, etc., for use at the longer wavelength telecommunication bands. From the materials perspective, the PFCBs not only possess the requisite low surface energy that permit such small patterns but 


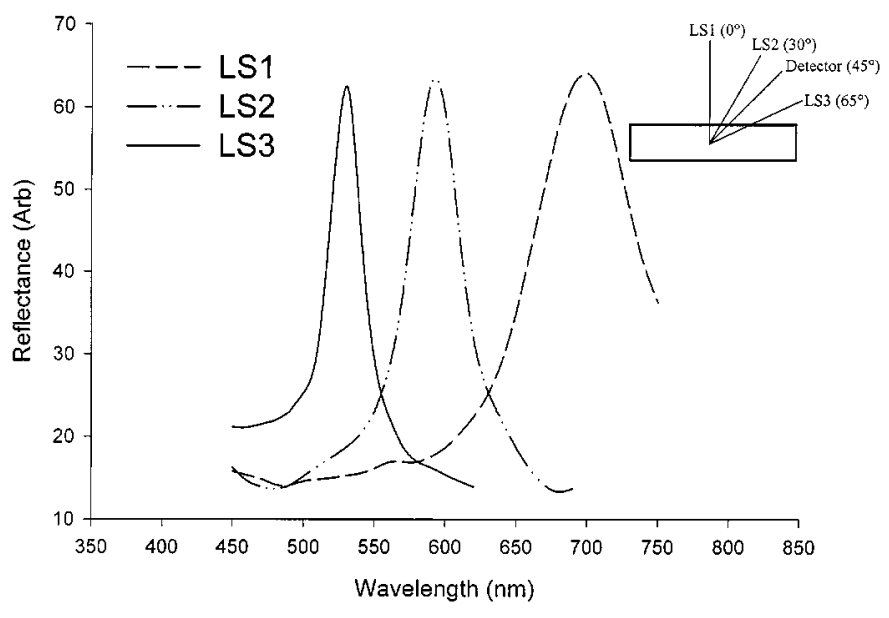

Fig. 3. Reflectivity of the linear gratings of Fig. 2 as a function of wavelength for a number of angles so defined in the inset.

also possess a wide copolymerization range, the ability to be functionalized with active or nonlinear moieties [10], and the lack of absorptive vibrational overtones in the near infrared. This list of complementary features marks both the materials and the process as deserving of consideration toward low-cost, high-throughput, multifunctional photonic, and optoelectronic devices. Toward this end, efforts currently are underway in our lab to characterize the performance of PFCB-based waveguides and other planar photonic devices that are fabricated by such direct soft lithographic approaches.

\section{CONCLUSION}

Submicrometer $(0.58 \mu \mathrm{m})$ linear gratings with $1-\mu \mathrm{m}$ deep steps have been micropatterned into a PFCB polymer directly from a silicon master. Diffraction effects in the visible clearly are observable from the resultant thin-film structure. This novel "negative mold-free" technique simplifies the fabrication process by eliminating several steps from the conventional soft lithographic methods and produces planar PFCB microstructures with feature sizes applicable to photonic applications in the visible and at the longer wavelength telecommunication bands.

\section{ACKNOWLEDGMENT}

M. Radler and C. Langhoff (Dow) are acknowledged for assistance with optical characterization.

\section{REFERENCES}

[1] B. Lee, M. Kwon, J. Yoon, and S. Shin, "Fabrication of polymeric large-core waveguides for optical interconnects using a rubber molding process," IEEE Photon. Technol. Lett., vol. 12, pp. 62-64, Jan. 2000.

[2] U. Siebel, R. Hauffe, and K. Petermann, "Crosstalk-enhanced polymer digital optical switch based on a W-shape," IEEE Photon. Technol. Lett., vol. 12, pp. 40-41, Jan. 2000.

[3] M. Oh, M. Lee, and H. Lee, "Polymeric waveguide polarization splitter with a buried birefringent polymer," IEEE Photon. Technol. Lett., vol. 11, pp. 1144-1146, 1999.

[4] N. Stutzmann, T. Tervoort, C. Bastiaansen, K. Feldman, and P. Smith, "Solid-state replication of relief structures in semicrystalline polymers," Adv. Mater., vol. 12, pp. 557-562, 2000.

[5] J. Harmon, Ed., Advances in Optical Fibers and Waveguides. New York: Oxford Univ. Press, 1999, vol. 40, p. 1256.

[6] D. Babb, B. Ezzell, K. Clement, W. Richey, and A. Kennedy, "Perfluorocyclobutane aromatic ether polymers," J. Polym. Sci. A, Polym. Chem., vol. 31, pp. 3465-3477, 1993.

[7] D. Smith Jr., H. Boone, R. Traiphol, H. Shah, and D. Perahia, "Perfluorocyclobutyl liquid crystalline fluoropolymers. Synthesis and thermal cyclopolymerization of bis(trifluorovinyloxy)-alpha-methylstilbene," Macromolecules, vol. 33, pp. 1126-1128, 2000.

[8] D. Smith Jr., D. Babb, H. Shah, A. Hoeglund, R. Traiphol, D. Perahia, H. Boone, C. Langhoff, and M. Radler, "Perfluorocyclobutane (PFCB) polyaryl ethers: Versatile coatings materials," J. Fluorine Chem., vol. 104, pp. 109-117, 2000.

[9] G. Fischbeck, R. Moosburger, C. Kostrzewa, A. Achen, and K. Petermann, "Singlemode optical waveguides using a high temperature stable polymer with low losses in the $1.55 \mu \mathrm{m}$ range," Electron. Lett., vol. 33, pp. 518-519, 1997.

[10] H. Ma, J. Wu, P. Herguth, B. Chen, and A. K.-Y. Jen, "A novel class of high-performance perfluorocyclobutane-containing polymers for second-order nonlinear optics," Chem. Mater, vol. 12, pp. 1187-1189, 2000.

[11] D. Qin, Y. Xia, J. Rogers, R. Jackman, X. Zhao, and G. Whitesides, "Microfabrication, microstructures and microsystems," in Microsystem Technology in Chemistry and Life Sciences, A. Manz and H. Becker, Eds. Berlin, Germany: Springer-Verlag, 1998, vol. 194, pp. 1-20.

[12] H. Shah, S. Brittain, Q. Huang, S. Hwu, G. Whitesides, and D. Smith Jr., "Bis-ortho-diynylarene (BODA) derived polynaphthalenes as precursors to glassy carbon microstructures," Chem. Mater., vol. 11, pp. 2623-2625, 1999.

[13] M. J. Owens, Physical Properties of Polymer Handbook, J. E. Mark, Ed. Woodbury, NY: AIP, 1996, p. 674. 